\title{
Evaluasi Penggunaan Antibiotik Pada Pasien Dispepsia Komplikasi Demam Tifoid di Rumkit Putri Hijau Medan 2018
}

\author{
Desy Natalia Siahaan 1,*, Burham ${ }^{2}$, Reny Ayu Zendrato ${ }^{1}$ \\ ${ }^{1}$ Fakultas Farmasi, Sarjana Farmasi, Universitas Tjut Nyak Dhien, Medan, Indonesia \\ ${ }^{2}$ Rumah Sakit Putri Hijau, Medan, Indonesia \\ Email: 1desshn@gmail.com
}

\begin{abstract}
Abstrak-Antibiotik adalah zat yang dihasilkan oleh suatu mikroorganisme hidup terutama jamur yang dapat menghambat atau dapat membunuh mikroba jenis lain. Penggunaan antibiotik yang tinggi dapat memicu penggunaan antibiotik yang tidak rasional.Penelitian ini bertujuan untuk mengetahui kuantitas dan kualitas serta pola penggunaan antibiotik di ruang rawat inap pada pasien dispepsia dan komplikasi demam tifoid di Rumah Sakit TK II Putri Hijau Kesdam I/BB Medan pada periode 2018.

Penelitian yang dilakukan bersifat deskriptif dengan desain penelitian cross sectional dengan pengambilan data dilakukan secara retrospektif selama periode 2018.Parameter evaluasi kuantitatif menggunakan metode DDD (Defined Daily Dose) dan evaluasi kualitatif menggunakan kategori Gyssens.Hasil penelitian menunjukkan bahwa dari 120 pasien yang menggunakan antibiotik, dengan penilaian kualitas kategori Gyssens didapatkan hasil sebesar 90\% kategori 0 (rasional), 10\% kategori IIIA (durasi terlalu lama). Penilaian kuantitas dengan metode DDD (Defined Daily Dose) didapatkan penggunaan antibiotik dengan nilai DDD/1000 patientdays yang paling tinggi adalah golongan fluorokuinolon (siprofloksasin dan levofloksasin) dengan 56,4 \%, dimana untuk siprofloksasin memiliki 1.213 DDD/1000 Patient-day dan untuk levofloksasin memiliki 1.000 DDD/1000 Patient-day . Antibiotik untuk golongan sefalosporin generasi ketiga (sefotasim dan seftriakson) dengan 43,14 \%, dimana untuk sefotasim memiliki 713 DDD/1000 Patient-day dan untuk seftriakson memiliki 1.000 DDD/1000 Patient-day.
\end{abstract}

Kata Kunci: Antibiotik; Dispepsia; Tifoid; Gyssens; ATC/DDD/1000 Days

Abstract-Antibiotics are substances that are produced by microorganisms that live from fungi that can fight or can fight other types of microbes. The use of higher antibiotics can be used in the use of antibiotics that are not rational. This research aims to improve the quality and quality of antibiotic use in inpatients at Patients with dyspepsia and complications of typhoid fever at TK Hijau Putri II Hospital, Kesdam I / BB Medan in 2018. The study was conducted descriptive descriptive with cross sectional research design with retrospective data collection conducted during the 2018 period. Quantitative evaluation research used the DDD (Defined Daily Dose) method and qualitative evaluation using the Gyssens category.The results showed that of the 120 patients using antibiotics, the quality assessment of the Gyssens category obtained results of $90 \%$ category 0 (rational), $10 \%$ category IIIA (duration too long). Evaluation of the amount by the DDD method (Daily Dose Determined) obtained the use of antibiotics with a DDD value / 1000 patient-day the highest was the fluoroquinolone group (ciprofloxacin and levofloxacin) with $56.4 \%$, while for ciprofloxacin used 1,213 DDD / 1000 Patient-day and for levofloxacin have 1,000 DDD / 1000 Patient-days. Antibiotics for the third generation cephalosporins (cefotasim and ceftriaxone) with 43.14\%, while for cefotasim have 713 DDD / 1000 Patient-days and for ceftriaxone have 1,000 DDD / 1000 Patient-days.

Keywords: Antibiotics; Dyspepsia and Complications of Typhoid Fever; Gyssens Method; ATC / DDD Method

\section{PENDAHULUAN}

Dismotilitas saluran cerna bagian atas menimbulkan keluhan-keluhan saluran cerna berupa mual, muntah, nyeri ulu hati, rasa terbrakar didada, kembung, anoreksia. Sedangkan dismotilitas saluran cerna bagian bawah biasa menimbulkan keluhan diare, kontipasi, sakit perut bawah, kembung. Dimotilitas saluran cerna bagian atas yang sering didapatkan yaitu sindrom dispepsia dan gastroesophageal reflux disease (GERD). Dismotilitas usus halus dan kolon yang sering didapatkan yaitu sindrom kolon iritabel (IBS) (Setiati,S, dkk, 2015).

Dispepsia merupakan kumpulan gejala berupa rasa nyeri atau ketidaknyamanan yang berpusat di perut bagian atas. Rasa tidak nyaman secara spesifik meliputi rasa cepat kenyang, rasa penuh, rasa terbakar, kembung di perut bagian atas dan mual. Gejala tersebut bersifat umum dan merupakan 30\% sampai $40 \%$ dari semua keluhan lambung yang disampaikan kepada dokter ahli Gastroenterologi (Jamil O, 2016 ).

Gejala-gejala yang timbul disebabkan berbagai faktor seperti gaya hidup merokok, alkohol, berat badan berlebih, stres, kecemasan, dan depresi terjadinya dispepsia (Abdullah \& Gunawan, 2015). Kebiasaan mengkonsumsi makanan dan minuman, seperti makan pedas, asam, minum teh, kopi, dan minuman berkarbonasi dapat meningkatkan resiko munculnya gejala dispepsia. Suasana yang sangat asam di dalam lambung dapat membunuh organisme patogen yang tertelan bersama makanan. Namun, bila barier lambung telah rusak, maka suasana yang sangat asam di lambung akan memperberat iritasi pada dinding lambung (Herman, 2014).

Berdasarkan penelitian pada populasi umum didapatkan bahwa 15-30\% orang dewasa pernah mengalami dispepsia dalam beberapa hari. Negara-negara di Barat (Eropa) memiliki angka prevalensi sekitar 7-41\%, tetapi hanya 10-20\% yang akan mencari pertolongan medis. Angka insiden dispepsia diperkirakan sekitar 1-8\%. Sedangkan di Indonesia belum didapatkan data epidemiologi yang pasti. Menurut data Profil Kesehatan Indonesia 2007, dispepsia sudah menempati peringkat ke-10 untuk kategori penyakit terbanyak pasien rawat inap di rumah sakit tahun 2006 dengan jumlah pasien 34.029 atau sekitar 1,59\%. Sedangkan insiden kasus dispepsia di RSUP Dr. M. Djamil yang diambil dari data IDT pada tahun 2011 sebanyak 231 orang (Widya I, 2016).

Salmonella typhi (S. typhi) merupakan kuman patogen penyebab demam tifoid, yaitu suatu penyakit infeksi sistemik dengan gambaran demam yang berlangsung lama, adanya bakteremia disertai inflamasi. Demam tifoid 


\section{Journal of Pharmaceutical and Health Research}

Vol 2, No 2, Juni 2021, pp. 54-59

ISSN 2721-0715 (media online)

DOI 10.47065/jharma.v2i2.913

merupakan penyakit menular yang tersebar di seluruh dunia, dan sampai sekarang masih menjadi masalah kesehatan terbesar dinegara sedang berkembang dan tropis seperti Asia Tenggara, Afrika dan Amerika. Insiden penyakit ini masih sangat tinggi dan diperkirakan sejumlah 21 juta kasus dengan lebih dari 700 kasus berakhir dengan kematian 89. Di Indonesia, insiden demam tifoid diperkirakan sekitar 300-810 kasus per 100.000 penduduk per tahun, berarti jumlah kasus berkisar antara 600.000-1.500.000 pertahun. Hal ini berhubungan dengan tingkat higienis individu, sanitasi lingkungan dan penyebaran kuman dari karier atau penderita tifoid. Berdasarkan hasil survei kesehatan rumah tangga (SKRT) 1986 demam tifoid menyebabkan kematian 3\% dari seluruh kematian di Indonesia (Ulfa, 2018).

Antibiotik merupakan obat yang paling banyak digunakan pada infeksi yang disebabkan bakteri. Berbagai studi menemukan bahwa sekitar 40-62\% antibiotik digunakan secara tidak tepat antara lain untuk penyakit-penyakit yang sebenarnya tidak memerlukan antibiotik. Pada penelitian kualitas penggunaan antibiotik di berbagai bagian rumah sakit ditemukan 30\% sampai dengan 80\% tidak didasarkan pada indikasi (Hadi, 2018).

Penggunaan antibiotik yang tidak rasional dapat menyebabkan resistensi terhadap antibiotik. Resistensi merupakan dampak negatif dari pemakaian antibiotik yang irasional, penggunaan antibiotik dengan indikasi yang tidak jelas, dosis atau lama pemakaian yang tidak sesuai, cara pemakaian yang kurang tepat, status obat yang tidak jelas, serta pemakaian antibiotik secara berlebihan. Dampak lainnya dari pemakaian antibiotik secara irasional dapat berakibat meningkatkan toksisitas, dan efek samping antibiotik tersebut, serta biaya rumah sakit yang meningkat. Sehingga diperlukan penggunaan antibiotik berdasarkan diagnosis oleh tenaga medis profesional, monitoring dan regulasi penggunaan antibiotik untuk meningkatkan penggunaan antibiotik secara rasional (WHO, 2014).

Penggunaan antibiotik dapat dinilai secara kuantitas dengan Defined Daily Dose (DDD) yang menunjukkan asumsi dosis rata-rata perhari penggunaan antibiotik untuk indikasi tertentu pada orang dewasa dan secara kualitatif dengan metode Gyssens berdasarkan data rekam medik dan kondisi klinis pasien (Faizah Binfar, 2019). Metode Gyssens merupakan suatu alat untuk mengevaluasi kualitas penggunaan antibiotik yang sudah dipakai secara luas di berbagai Negara (OR Muhammad, 2018).

DDD merupakan rata-rata dosis pemeliharaan orang dewasa untuk indikasi yang utama dari suatu obat. DDD adalah suatu unit internasional yang dapat digunakan secara luas untuk menilai penggunaan obat termasuk antibiotik disarana pelayanan kesehatan (MG Sholih, 2019). Data konsumsi obat yang disajikan dalam DDD hanya memberikan perkiraan kasar dari penggunaan obat, bukan penggunaan obat yang sebenarnya karena DDD tidak memperhatikan usia, berat badan pasien dan pertimbangan farmakokinetik obat (Astuti, 2018). Jumlah pemakaian antibiotik yang memiliki kode ATC (dalam gram) dikonversi ke dalam unit DDD kemudian dihitung dalam satuan DDD/1000 patients days (Kemenkes RI, 2011)

\section{METODOLOGI PENELITIAN}

\subsection{Kerangka Konsep Penelitian}

Berikut merupakan kerangka dari penelitian yang dilakukan.

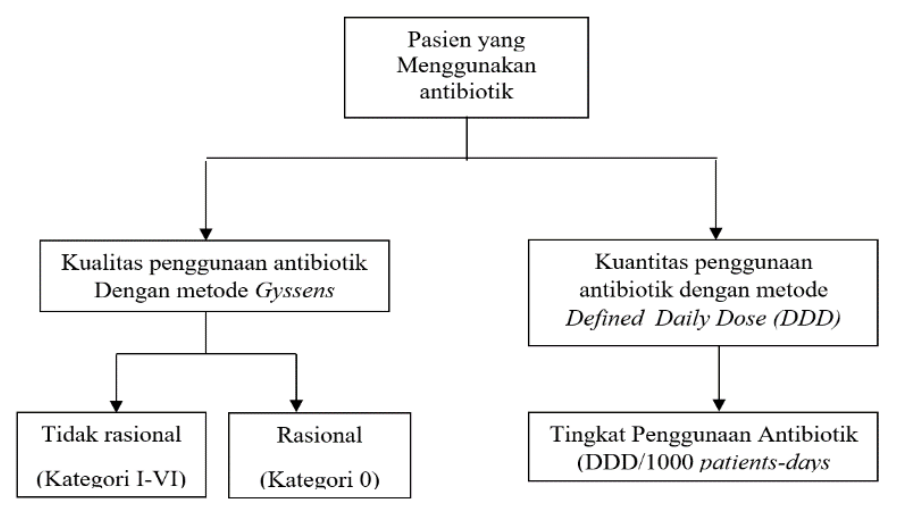

Gambar 1. Kerangka konsep penelitian

\subsection{Sampel Penelitian}

Pengambilan sampel secara non random purposive sampling yaitu pengambilan sampel berdasarkan kriteria inklusi. Sampel penelitian ini adalah seluruh pasien dengan diagnosa dispepsia komplikasi demam tifoid yang menggunakan obat antibiotik di Rumah Sakit TK II Putri Hijau Kesdam I/BB Medan pada tahun 2018 yang memenuhi kriteria inklusi.

\subsection{Pengelolaan data}

Evaluasi kualitas penggunaan antibiotik berdasarkan diagram alur Gyssens meliputi dosis dan interval antibotik, lama pemberian antibiotik, efektivitas, dan toksisitas antibiotik, harga, spektrum, dan indikasi penggunaan antibiotik. Pedoman yang digunakan untuk peneitian kualitas antibiotik adalah :Formularium Nasional tahun 2014, Pedoman 


\section{Journal of Pharmaceutical and Health Research}

Vol 2, No 2, Juni 2021, pp. 54-59

ISSN 2721-0715 (media online)

DOI 10.47065/jharma.v2i2.913

umum penggunaan antibiotik (Kemenkes, 2011) dan hasil pemeriksaan klinis dan laboratorium pasien. Evaluasi kualitas antibiotik dilakukan dengan menggunakan metode Gyssens yang terbagi dalam 0-VI katagori dan dinyatakan dalam persen. Evaluasi kuantitas penggunaan antibiotik (DDD/1000 patient-days). Nilai DDD/1000 patient-days merupakan nilai pengukuran kuantitas antibiotik yang dikeluarkan oleh WHO. Pada penelitian ini digunakan DDD/1000 patient days dengan rumus perhitungan :

$\frac{\text { Jumlah antibiotik yang digunakan pasien (gram) }}{\text { Standar WHO DDD (gram) }} \times \frac{1000}{\text { Total LOS }}$

Keterangan :

Lengh of stay (LOS) : Lama rawat inap pasien (terhitung sejak hari pertama pasien masuk rumah sakit sampai dengan hari dimana pasien keluar dari rumah sakit) yang didapat dari rekam medik yang terpilih sebagai sampel selama tahun 2018 (Rahayu, 2017).

\section{HASIL DAN PEMBAHASAN}

\subsection{Jenis Antibiotik}

Berdasarkan penelitian yang telah di lakukan dari 120 pasien rawat inap dibagian penyakit dalam Rumah Sakit TK II Putri Hijau Kesdam I/BB Medan pada periode 2018 yang masuk dalam kriteria inklusi, ada 4 jenis antibiotik yang digunakan meliputi antibiotik golongan sefalosporin generasi ketiga (seftriakson, sefoktasim) dan fluroquinolon (siprofloksasin, levofloksasin).

Tabel 1. Jenis Antibiotik yang Digunakan Pasien Selama di Rawat di Rumah Sakit TK II Putri Hijau KESDAM I/BB Medan

\begin{tabular}{ccccc}
\hline No & Golongan Antibiotik & Jenis Antibiotik & Jumlah & Persentase \% \\
\hline 1 & Fluorokuinolon & Siprofloksasin & 25 & 20,8 \\
& & Levofloksasin & 27 & 22,5 \\
2 & Sefalosporin Generasi & Sefotasim & 14 & 11,7 \\
& Ketiga & Seftriakson & 54 & 45 \\
\hline & Total & & 120 & 100 \\
\hline
\end{tabular}

Dari tabel 1 golongan antibiotik yang paling sering digunakan adalah golongan sefalosporin generasi ketiga yaitu seftriakson dengan persentase $45 \%$. Seftriakson mampu menurunkan suhu tubuh hungga normal secara signifikan sehingga dapat menjadi obat pilihan untuk pasien demam tifoid (Hammad, 2015). Antibiotik kedua yang banyak digunakan adalah golongan fluorokuinolon yaitu levofloksasin dengan persentase 22,5\%. Antibiotik siprofloksasin dengan persentase $20,8 \%$. Siprofloksasin sangat dianjurkan untuk demam tifoid karena lebih toleran dan menimbulkan efek yang baik pada pasien demam tifoid (Nathin,2015). Antibiotik Sefotasim dengan persentase $11,7 \%$. Sefotasim mempunyai spektrum kerja yang luas dan aktif terhadap kuman gram positif dan gram negatif (Tjay dan Raharjo, 2017).

\subsection{Variasi Antibiotik}

Berdasarkan hasil penelitian dari 120 rekam medik yang masuk dalam kriteria inklusi, didapatkan distribusi variasi antibiotik jenis antibiotik yang diresepkan kepada tiap pasien selama perawatan, seperti yang tercantum pada tabel 2.

Tabel 2. Variasi Antibiotik pada Pasien Selama di Rawat di Rumah Sakit TK II Putri Hijau KESDAM I/BB Medan

\begin{tabular}{ccc}
\hline Jumlah Jenis Antibiotik Tiap Pasien & Jumlah & Persentase \% \\
\hline Tunggal & 120 & 100 \\
Kombinasi & 0 & 0 \\
\hline Total & 120 & 100 \\
\hline
\end{tabular}

Dari tabel 2 yang paling banyak persentasenya yaitu 1 jenis antibiotik sebanyak 100\%. Penggunaan antibiotik tunggal biasanya digunakan pada demam tifoid. Hasil penelitian ini sama dengan penelitian sebelumnya yang dilakukan oleh Nurlaila (2015) menunjukkan bahwa antibiotik yang paling banyak digunakan dari golongan sefalosporin generasi ke tiga yaitu seftriakson, sefiksim dan sefoktasim. Antibiotik terbanyak kedua adalah dari golongan fluorokuinolon yaitu siprofloksasin dan levofloksasin (Nuraini, 2015).

\subsection{Kualitas Antibiotik (Metode Gyssens)}

Penilaian penggunaan antibiotik secara kualitas dilakukan dengan menggunakan metode Gyssens yang terbagi dalam 0VI kategori, menurut gyssens penilaian ini membutuhkan kelengkapan data agar dapat dinilai secara cermat oleh seorang peneliti kemudian dikelompokkan ke dalam kategori yang sesuai tabel 3.8 menunjukkan penggunaan antibiotik secara kualitas berdasarkan metode gyssens pada pasien dispepsia komplikasi demam tifoid rawat inap di Rumah Sakit TK II Putri Hijau Kesdam I/BB Medan pada periode 2018. 
Journal of Pharmaceutical and Health Research

Vol 2, No 2, Juni 2021, pp. 54-59

ISSN 2721-0715 (media online)

DOI 10.47065/jharma.v2i2.913

Tabel 3. Kualitas Antibiotik (Metode Gyssens) pada Pasien Selama di Rawat di Rumah Sakit TK II Putri Hijau KESDAM I/BB Medan

\begin{tabular}{clcc}
\hline Kategori & \multicolumn{1}{c}{ Kategori Gyssens } & Jumlah & Persentase \% \\
\hline O & Penggunaan antibiotik tepat/rasional & 108 \\
I & Tidak tepat saat (timing) pemberian antibiotic & \\
IIA & Tidak tepat dosis pemberian antibiotik & \\
IIB & Tidak tepat interval antibiotic & \\
IIC & Tidak tepat rute pemberian antibiotik & 12 & 10 \\
IIIA & Pemberian antibiotik terlalu lama & \\
IIIB & Pemberian antibiotik terlalu singkat & \\
IVA & Tidak tepat pilihan antibiotik karena ada antibiotik lain yang lebih & \\
& efektif & \\
IVB & Tidak tepat pemberian antibiotik karena ada antibiotik lain yang & \\
IVC & kurang toksik & & \\
& Tidak tepat pilihan antibiotik karena ada antibiotik lain yang lebih & \\
IVD & murah & Tidak tepat pilihan antibiotik karena ada antibiotik lain spektrum & \\
& lebih sempit & \\
V & Tidak ada indikasi pemberian obat & \\
VI & Data tidak lengkap sehingga penggunaan antibiotik tidak dapat di & \\
& nilai & \\
\hline
\end{tabular}

Berdasarkan data hasil penelitian pada pasien rawat inap dibagian penyakit dalam Rumah Sakit TK II Putri Hijau Kesdam I/BB Medan pada periode 2018, hanya ada beberapa kategori gyssens (IIIA dan 0) dari 13 kategori gyssens yang masuk dalam penilain kualitas penggunaan antibiotik. Hasil penelitian menunjukkan penggunaan antibiotik yang memenuhi kategori gyssens 0 (tepat penggunaan antibiotik) adalah sebesar $90 \%$ dan kategori IIIA (penggunaan antibiotik terlalu lama) sebesar $10 \%$.

Kategori IIIA (penggunaan antibiotik terlalu lama). Sebanyak 120 rekam medik ada 12 rekam medik antibiotik yang masuk kategori ini. Antibiotik yang termasuk dalam kategori ini adalah sefotasim dengan lama penggunaan 6 dan 7 hari, seharusnya antibiotik sefotasim digunakan selama 3 sampai 5 hari (Kemenkes, 2006). Penggunaan sefotasim terlalu lama karena kondisi pasien yang belum terlalu membaik sehingga dokter tetap meneruskan pemberian sefotasim. Kategori 0 (Penggunaan antibiotik tepat/rasional). Sebanyak 120 rekam medik ada 108 rekam medik antibiotik yang masuk kategori ini. Antibiotik yang termasuk dalam kategori ini adalah seftriakson dengan lama penggunaan $3-5$ hari, sefotasim dengan lama penggunaan 5-6 hari, siprofloksasin dengan lama penggunaan 5-6 hari, levofloksasin dengan lama penggunaan 4-5 hari. Hal ini sesuai dengan prinsip penggunaan antibiotik yang benar yang terdapat didalam KEMENKES No. 364 tahun 2006 tentang pedoman pengendalian demam tifoid.

\subsection{Kuantitas Penggunaan Antibiotik (DDD/1000Patient-Days)}

Kuantitas penggunaan antibotik dihitung menggunakan metode DDD/1000 patient-days. Dari 120 pasien dispepsia dan komplikasi demam tifoid rawat inap dalam pada periode 2018, didapatkan data hasil perhitungan DDD untuk setiap pasien antibiotik pada pasien sebagai berikut:

Tabel 4. Kuantitas Penggunaan Antibiotik (DDD/1000 Patient-Days) pada Pasien Selama di Rawat di Rumah Sakit TK II Putri Hijau KESDAM I/BB Medan

\begin{tabular}{|c|c|c|c|c|c|c|c|}
\hline No & $\begin{array}{c}\text { Golongan } \\
\text { Antibiotik }\end{array}$ & $\begin{array}{c}\text { Jenis } \\
\text { Antibiotik }\end{array}$ & $\begin{array}{l}\text { Kode } \\
\text { ATC }\end{array}$ & $\begin{array}{c}\text { Nilai } \\
\text { Standar } \\
\text { DDD WHO }\end{array}$ & $\begin{array}{c}\text { Nilai Standar } \\
\text { DDD/1000Pa } \\
\text { tient- } \\
\text { Days }\end{array}$ & $\begin{array}{c}\text { Persentase } \\
\%\end{array}$ & Total \\
\hline \multirow[t]{2}{*}{1} & $\begin{array}{c}\text { Fluorokuin } \\
\text { olon }\end{array}$ & $\begin{array}{l}\text { Siprofloks } \\
\text { asin }\end{array}$ & $\begin{array}{c}\text { J01MA } \\
02\end{array}$ & $1(\mathrm{O}) ; 0,8(\mathrm{P})$ & 1.213 & 30,09 & 56,4 \\
\hline & & $\begin{array}{l}\text { Levofloksa } \\
\sin \end{array}$ & $\begin{array}{c}\text { J01MA } \\
12\end{array}$ & $\begin{array}{l}0,5(\mathrm{O}) ; 0,5 \\
(\mathrm{P})\end{array}$ & 1.000 & 25,5 & \\
\hline \multirow[t]{3}{*}{2} & $\begin{array}{l}\text { Sefalospori } \\
\text { n Generasi }\end{array}$ & Sefotasim & $\begin{array}{c}\text { J01DD } \\
01\end{array}$ & $4(\mathrm{P})$ & 713 & 18,2 & 43,6 \\
\hline & Ketiga & Seftriakson & $\begin{array}{c}\text { J01DD } \\
04\end{array}$ & $2(\mathrm{P})$ & 1.000 & 2655 & \\
\hline & & Total & & & 3.526 & 100 & 100 \\
\hline
\end{tabular}

Tabel 4 menunjukkan bahwa golongan antibiotik fluorokuinolon (siprofloksasin dan levofloksasin) dengan total $56,4 \%$. Jumlah pemberian antibiotik siprofloksasin pada pasien sebanyak 25 pasien dengan dosis $1 \mathrm{~g} / 6$ jam, 4x1 dan jumlah pemberian antibiotik levofloksasin pada pasien sebanyak 27 orang dengan dosis 500mg/24 jam, 1x1. Golongan 


\title{
Journal of Pharmaceutical and Health Research
}

\author{
Vol 2, No 2, Juni 2021, pp. 54-59
}

ISSN 2721-0715 (media online)

DOI 10.47065/jharma.v2i2.913

sefalosporin generasi ketiga (sefotasim dan seftriakson) dengan total 43,6\%. Jumlah pemberian antibiotik sefotasim pada pasien sebanyak 14 pasien dengan dosis $500 \mathrm{mg} / 12$ jam,2x1 dan jumlah pemberian antibiotik seftriakson pada pasien sebanyak 54 orang dengan dosis $1 \mathrm{~g} / 12 \mathrm{jam}, 2 \mathrm{x} 1$.

\section{KESIMPULAN}

Berdasarkan hasil penelitian dengan metode Gyssens, kategori 0 (penggunaan antibiotik yang rasional) sebesar 90\%, kategori IIIA (penggunaan antibiotik terlalu lama) sebesar 10\%.Antibiotik dengan nilai DDD/1000 patient-days yang paling tinggi adalah golongan fluorokuinolon (siprofloksasin dan levofloksasin) dengan 56,4 \%, dimana untuk siprofloksasin memiliki 1.213 DDD/1000 Patient-day dan untuk levofloksasin memiliki 1.000 DDD/1000 Patient-day. Antibiotik untuk golongan sefalosporin generasi ketiga (sefotasim dan seftriakson) dengan 43,6\%, dimana untuk sefotasim memiliki 713 DDD/1000 Patient-day dan untuk seftriakson memiliki 1.000 DDD/1000 Patient-day.

\section{DAFTAR PUSTAKA}

Abdullah, M., Gunawan, J. (2015). Dispepsia Continung Medical Education, Vol.39, n0.9. Halaman 647-670.

Adriani, K.P. (2015). Evaluasi Rasionalitas Penggunaan Antibiotik Pada Pasien Dewasa di Instalasi Rawat Inap RS Bethesda Yogyakarta. Skripsi. Universitas Gadja Mada.

Amalia Shofia. (2016). Studi Penggunaan Antibiotik. Skripsi. Universitas Airlangga. Surabaya.

Astuti Dea. (2018). Penggunaan Antibiotik Berdasarkan Metode ATC/DDD. Jakarta

Ciptaningtyas Rizke V. (2014). Antibiotik Untuk Mahasiswa Kedokteran. Yogyakarta: Graha Ilmu. Hal 20-45.

Daftar DDD antibiotik/WHOCC-ATC/DDD WHOCC-ATC/DDD index. (2006). (http://www.whocc.no/atc/dddindex).Diakses pada 9 Desember 2019

Depkes RI. (2009). Sistem Kesehatan Nasional.Jakarta.Diakses pada 18 Januari 2020

Dewi, A.P. (2018). Penggunaan Antibiotik Pada Pasien Demam Tifoid Rawat Inap Di Rumah Sakit Islam Klaten. Skripsi. Universitas Setia Budi Surakarta.

Faizah Binfar. (2019). Pedoman Pelayanan Kefarmasian Untuk terapi Antibiotik Kementrian kesehatan Republik Indonesia. Jakarta: Departemen Kesehatan Republik Indonesia. Hal. 125

GyssensIC.,dkk.(2005).AuditforMonitoringtheQualtyofantimicrobial prescriptionNewYorkKlowerAcodemicpublisher.Halaman197-207

Hadi,U.,DUERINK,D.O.,Lestari,E.S.,Nagelkerke,N.J.,Keuter,M.,Suwandojo.E.,Rahardjo,E.,Vanden Broek,P.,dan Gyssens,I.C. (2018). Audit of antibiotic prescribing in two governmental teaching hospitals in Indonesia.Clinical Microbiology and infectious Discase Journal.Hal.698-707

Hammad,O.M., Hifnawy,T.,Omran,D.,Tantawi,m.A.\&Girgis,N.I.(2015).Ceftriaxone versus Chloramphenicol for Treatment of Acure Typhoid Fever.Life Scrience Journal,8(2).100-105

Harrison.(2014).Prinsip-prinsip Ilmu Penyakit Dalam.Buku Kedokteran.Yogyakarta.Hal.249-251

Herman,B.R.(2014).Fisiologi Pencernaan untuk Kedokteran.Padang:Andalas University Pross.Halaman 45-60

Ikatan Dokter Indonesia, (2015). Panduan Praktik Klinis Bagi Dokter.Jakarta:Pengurus Besar Ikatan Dokter Indonesia.

Irawan Ahmad. (2017). Pengaruh Kepatuhan Penggunaan Obat Terhadap Kualitas Hidup Pada Pasien Dispepsia Di Instalasi Farmasi Rumah Sakit Umum Daerah Dr. Moewardi Surakarta. Skripsi. Fakultas Farmasi Universitas Setia Budi Surakarta.

Jamil O.,Sawar,Hussain.Z.,Friaz R.and Haudry R.(2016).Association Between Functional Dyspepsia and Severity of Depression,Journal of the College of Physicians and Surgeons-Pakistan:JCPSP,26(6).Halaman 13-60

Kementrian Kesehatan RI.(2011).Modul Peraturan Menteri Kesehatan Republik Indonesia.Pedoman Umum Penggunaan Antibiotik. Jakarta.Hal 255-237

Keputusan Menteri Kesehatan RI No.364.(2006).Pedoman Pengendalian Demam Tifoid Menteri Kesehatan RI.Jakarta.Hal 1-38

Kristyasari .W.A.(2019).Evaluasi Penggunaan Antibiotik Pada Pasien Pediatrik Demam Tifoid Dengan Metode GYSSENS di RSUD Kota Yogyakarta Tahun 2016-2017,Skripsi.Fakultas Farmasi Universitas Sanata Dharma Yogyakarta.

Kurniaawati Hani Laila. (2019). Hubungan Pengetahuan Masyarakat Terhadap Perilaku Penggunaan Antibiotik. Skripsi. Fakultas Kedokteran Universitas Islam Negeri Maulana Malik. Malang.

Lacy et al.(2019). Motor disoders of the Quality of gastrointestinal tract:What new \& what to do. Academy professional information services ins. New York.USA

Lastiawan,S.(2017).Metodologi penelitian Kesehatan. Jakarta:Rhineka cipta.Hal.23

Lili MA,Fuad A,Gani A,Andayani P.Pla.(2015). Pemberian Antibiotik Pengobatan Demam Tifoid di Rumah Sakit Fatmawati.Jakarta.Makalah Kesehatan.Hal 27

Medscape. (2018). Drug Interction Checker. Medscape (http://reference.medscape.com/drug-interactionchecker accessed. Di akses pada tanggal 15 Desember 2019.

Muhammad OR.(2018).Penggunaan Antibiotik Berdasarkan Metode ATC/DDD.Jakarta

Nathin,R.(2015).Buku Ajar Ilmu Penyakit Dalam Jilid III Edisi IV :Pemakaian Antimikroba Secara Rasional Di Klinik.Jakarta:Penerbit Buku Kedokteran EGC,pp.1700

Novita Yulinda. (2019).Pravelensi Demam Tifoid Berdasarkan Jenis Kelamin Pada Pasien Rawat jalan di Rumah Sakit UIIN Syarifhidayatullah.Skripsi Jakarta.

Nuraini,F.A.,Garna Herry,Respati titik.(2015).Perbandingan Kloramfenikol dengan Seftriakson terhadap Lama Hari turun Demam pada Anak Demam Tifoid,Skripsi.Fakultas Kedokteran Universitas Islam Bandung,Bandung

Nuruzzaman,H.(2016)Analis Resiko Kejadian Demam Tifoid.Skripsi.Universitas Pancasila

Patria,P.(2019).Evaluasi Penggunaan Antibiotik pada Pasien Demam Tifoid Di RS TK II Putri Hijau Kesdam I/BB/Medan.Skripsi.Fakultas Farmasi.Universitas Tjut Nyak Dhien Medan.Hal 29 


\section{Journal of Pharmaceutical and Health Research}

Vol 2, No 2, Juni 2021, pp. 54-59

ISSN 2721-0715 (media online)

DOI 10.47065/jharma.v2i2.913

Peraturan Mentri Kesehatan.(2011).Pedoman Umum Penggunaan Antibiotik.(http://www.binfar.depkes.go.id/.dat/Permenkes Antibiotik.pdf)Diakses pada tanggal 20 Oktober 2019

Pramita,OP.(2014).Faktor Resiko Kejadian Penyakit Demam Tifoid Pada Pasien Penderita Yang Dirawat Di Rumah Sakit Umum Daerah Ungaran.Jurnal kesehatan masyarakat.(http://ejournal1.undip.ac.id/index.php/jkm.diakses pada tanggal 9 Desember 2019

Rahayu Sri.(2017).Evaluasi Penggunaan Antibiotik Secara Kualitas dan Kuantitas disertai Tingkat Resistensi dan Pola Kuman di Bagian Penyakit Dalam Rsup H. Adam Malik.Skripsi.Universitas Tjut Nyak Dhien Medan

Rampengan,H.R.(2016).Faktor yang Berhubungan Dengan Lama Hari Rwat Inap RSUD Pangkep.ISSN.Skripsi. Univerjitas Gadja Mada. Yogyakarta

Rao KA,Yazaki E,Evan,DF,Carron R.(2014).Objective evaluation of small bawel and calonic transit time with $\mathrm{Ph}$ telemetry in athletes with gastrointestinal symptoms.Br J Sports Med 20014;38:482-7

Rokhman.(2019).Faktor-Faktor Resiko Yang Berpengaruh Terhadap Kejadian Demam Tifoid Pada Orang Dewasa.Tesis. Yogyakarta: Universitas Gajah Mada

Setiati,S,Alwi,I,Sudoyo,AW,Simadibrata,M,Setiyohadi,B,Syam,AF.(2015).Ilmu Penyakit Dalam.Jakarta pusat:Buku Ajar, hal 17701811

Sholeh M.G.(2019).Gambaran Penggunaan Antibiotik Berdasarkan Metode ATC/DDD.Journal.Padang

Sidabutar,S.,Satari,H,I.(2017).Pilihan Terapi Empiris Demam Tifoid pada Anak:Kloramfenikol atau Seftriakson.Journal.Sari Pedriati.11,434.9

Tjay Tan Hoan dan Kirana Rohardja.(2017).Obat-obat Penting Khasiat Penggunaan dan Efek-efek Sampingnya.Edisi Keenam,Hal 262.PT Elex Media Kampotido,Jakarta

Ulfa.(2018).Faktor-faktor yang Berhubungan dengan Kejadian Demam Tifoid.Journal.Yogyakarta

Widodo AW.2016.Evaluasi Penggunaan Dan Evektifitas Pemberian Antibiotik Pada Pasien Demam Tifoid DiInstalasi Rawat Inap Rsud Sukoharjo.Skripsi.Fakultas Farmasi.Universitas Muhammadiyah Jakarta.Hal 8

Widyasari I.(2016).Hubungan antara Kecemasan dan Tipe Kepribadian Introvert dengan Dispepsia Fungsional.Skripsi.Surakarta:Universitas Muhammadiyah Surakarta.Halaman 17-35

Word Health Organization.(2011).WHO Global Strategy for Contaiment of Antimicrobial Resistence. (http://who.int/drugresistance/WHO Global_Strategy_English.pdf) 2019.Swizerland:WHO.Hal.18.23-29

Word Health Organization.(2014).Antimicrobial Resistance.diakses pada tanggal 10 November 2019

Yunita T. (2017). Evaluasi Rasionalitas Penggunaan Antibiotika. Skripsi. Universitas Gadja Mada. Yogyakarta. 